\title{
Гибридная коронарная реваскуляризация с использованием мини-инвазивного маммарно-коронарного шунтирования (опыт одного центра)
}

\author{
Петков А. В. ${ }^{1}$, Поливенок И. В. ${ }^{2}$, Скибо Ю. Н. ${ }^{1}$, Бучнева О. В. ${ }^{2}$, Бойко В. В. ${ }^{2}$ \\ ${ }^{1}$ Харьковская медицинская академия последипломного образования \\ 2 ГУ «Институт общей и неотложной хирургии имени В. Т. Зайцева НАМН» (Харьков)
}

\begin{abstract}
Гибридная коронарная реваскуляризация (ГКР) сочетает в себе такие преимущества коронарного шунтирования и чрескожных коронарных вмешательств (ЧКВ), как надежный отдаленный результат и низкие перипроцедуральные риски.

Цель работы - анализ результатов ГКР с использованием мини-инвазивного маммарно-коронарного шунтирования (мини-МКШ) на основе опыта одного центра.

Материалы и методы. Мини-МКШ в переднюю межжелудочковую артерию (ПМЖА) под прямым визуальным контролем доступом через переднюю мини-торакотомию было проведено 30 пациентам. Восьмерым из них проведена ГКР.

Результаты иобсуждение. Висследуемой группене отмечено госпитальнойлетальности ипериоперационных инфарктов миокарда; к конверсиям не прибегали. Наиболее значимым осложнением было плохое заживление торакотомной раны, отмеченное у восьми пациентов (27\%), из которых у семи был сахарный диабет или ожирение, что, однако, не имело отдаленных негативных последствий. В отдаленном периоде наблюдали один летальный случай по невыясненным причинам через 13 месяцев после мини-МКШ. Еще у одного пациента произошел рецидив стенокардии через 4 года после ГКР вследствие окклюзии стента.

Выводы. Мини-МКШ является предпочтительной альтернативой ЧКВ у пациентов со сложными поражениями ПМЖА, особенно в центрах с ограниченными ресурсами. Оно также может быть использовано в качестве этапа ГКР в таких центрах, особенно у пациентов с дополнительными рисками или ограничениями для традиционного коронарного шунтирования.
\end{abstract}

Ключевые слова: мини-инвазивное маммарно-коронарное шунтирование, гибридная коронарная реваскуляризация.

Снижение травматичности хирургических вмешательств и улучшение их косметичности без ущерба для объема и качества основного этапа является неотъемлемой частью прогресса в хирургии, в том числе сердечно-сосудистой. В настоящее время из мини-доступов размером 5-8 см могут быть выполнены не только такие кардиохирургические операции, как протезирование или пластика аортального, митрального клапанов и операции на восходящей аорте, но и полноценное коронарное шунтирование без искусственного кровообращения [1]. Причем если для эндоскопических вмешательств на сердце (не говоря уже о роботизированных операциях) требуется специальный инструментарий и соответствующая аппаратура, то при использовании мини-доступов оснащение меняется не столь существенно, что делает их использование привлекательным в условиях ограниченных ресурсов [2]. Об этом говорит также и тот факт, что первым коронарным шунтированием (КШ) было маммарнокоронарное шунтирование с использованием торакотомии $[3,4]$.
Техническая простота, относительная дешевизна и пока безальтернативная надежность левой внутренней грудной артерии (ЛВГА) в качестве шунта в переднюю межжелудочковую артерию (ПМЖА) сохраняют операцию маммарно-коронарного шунтирования из мини-торакотомного доступа (мини-МКШ) в арсенале хирургических вмешательств при ишемической болезни сердца (ИБС), несмотря на то, что операции уже более 20 лет [5, 6]. Поскольку способ реваскуляризации (стентирование или шунтирование) других (неПМЖА) сосудистых бассейнов в отношении отдаленных результатов не столь принципиален, гибридная коронарная реваскуляризация (ГКР), включающая шунтирование ПМЖА посредством ЛВГА (одним из малоинвазивных способов) и чрескожные коронарные вмешательства (ЧКВ) на не-ПМЖА артериях, активно используется в различных клиниках, сочетая в себе преимущества традиционных шунтирований и ЧКВ надежный отдаленный результат и малотравматичность, в том числе косметичность и низкие периопроцедурные риски [7-9]. 
Целью исследования является анализ преимуществ и недостатков гибридной коронарной реваскуляризации с использованием мини-инвазивного маммарнокоронарного шунтирования на основе опыта одного центра.

Материалы и методы. В Институте в период с марта 2011 г. по март 2017 г. выполнено 30 мини-МКШ. Среди оперированных - четыре (13\%) женщины и 26 (87\%) мужчин. Возраст оперированных - от 42 до 77 лет, медиана составила 60 [55; 66] лет. Ожирение отмечено у шести (20\%) пациентов, сахарный диабет - у пяти (17\%). У семи (23\%) пациентов мини-МКШ явилось первым этапом запланированной ГКР, а у одного пациента мини-МКШ было проведено после ЧКВ на фоне острого инфаркта миокарда.

Мини-МКШ в качестве единственного вмешательства предлагали пациентам с поражением проксимальной части ПМЖА или хронической окклюзией в средней части, представляющей технические трудности для ЧКВ. ГКР предлагали пациентам с поражением ПМЖА в сочетании с благоприятными для проведения ЧКВ поражениями других сосудистых бассейнов, если для проведения традиционного коронарного шунтирования в полном объеме имелись потенциальные риски или препятствия: дефицит или непригодность аутовен, выраженный атерокальциноз восходящей аорты, тяжелая ишемия нижних конечностей, косметические предпочтения пациента.

Количественные переменные представлены в виде Ме [Q1;Q3], где Ме - медиана, Q1, Q3 - первый и третий квартили; категориальные переменные представлены в виде $\mathrm{n}(\%)$, т.е. абсолютной и процентной частоты встречаемости признака.

Методика операции. Для проведения мини-МКШ пациента укладывали на спину и проводили торакотомию в 4-м (27 пациентов) или 5-м (три пациента) межреберье слева. Выбор доступа определялся особенностями поражения передней межжелудочковой артерии по данным коронарографии и конституциональными особенностями пациента, дополненными данными обзорной рентгенографии органов грудной клетки в прямой проекции. После вскрытия плевральной полости пальпаторно оценивали расположение и ход ЛВГА, которую затем выделяли под прямым визуальным контролем, скелетизируя в пределах межреберного промежутка и в обе стороны от него на протяжении, достаточном для ее анастомозирования в целевой участок ПМЖА без натяжения, что оценивали после перикардиотомии. Взяв перикард на держалки, сегмент миокарда, содержащий целевой участок ПМЖА, стабилизировали оригинальным стабилизатором, фиксируя его к небольшому стандартному ранорасширителю. При отсутствии окклюзионного поражения ПМЖА использовали интракоронарный шунт. Пери- кард оставляли неушитым. Операцию завершали дренированием левой плевральной полости в 6-м или 7-м межреберье.

ЧКВ в качестве второго этапа гибридной стратегии реваскуляризации миокарда в запланированных случаях проводили пациентам в сроки 4-17 суток после проведения мини-КШ, удостоверяясь при этом в функционировании маммарного шунта.

Результаты и обсуждение. Все хирургические вмешательства выполнены в запланированном объеме, к конверсиям и повторным операциям решунтирования не прибегали. Случаев госпитальной летальности, периоперационных инфарктов миокарда не было. Интраоперационная кровопотеря не превышала 100 мл. Медиана продолжительности операций составила 180 [171; 209] минут. Длина кожного разреза составляла 7-9 см (в среднем около 8 см). Среди послеоперационных осложнений наиболее частым было плохое заживление операционной раны - 8 (27\%) случаев: в семи случаях при сахарном диабете или ожирении, в том числе при их сочетании). Также следует отметить перелом вышележащего ребра у четырех (13\%) пациентов (и сопутствующий этому выраженный болевой синдром), левосторонний плеврит у одного (3\%), плевропневмонию у одного (3\%), левосторонний гемоторакс, развившийся на третьи послеоперационные сутки и потребовавший редренирования левой плевральной полости, еще у одного (3\%) пациента.

При ГКР на этапе проведения ЧКВ шунтография показала хорошее функционирование маммарного шунта у всех пациентов. У пяти пациентов на этом этапе использовали по одному стенту, у троих - по два. Еще в трех случаях была реализована потенциально гибридная реваскуляризация миокарда: у пациентов с поражением ПМЖА и пограничными (40-50\%) поражениями не-ПМЖА артерий после этапа мини-МКШ отмечали полное устранение стенокардии (подтвержденное ЭКГ-тестами с физической нагрузкой), и этап ЧКВ был отложен на неопределенный срок.

В отдаленном периоде, медиана которого составила $2,0[1,1 ; 3,3]$ года, отмечен один летальный исход - через 13 месяцев после операции по неизвестной причине, а также один рецидив стенокардии по истечении 4 лет (вследствие окклюзии стента у пациентки с гибридной реваскуляризацией).

Таким образом, основным недостатком миниМКШ, по нашим данным, являются осложнения со стороны операционной раны, связанные, на наш взгляд, прежде всего с травмой тканей в зоне доступа на фоне их существенной деваскуляризации. Следует при этом отметить, что плохое заживление операционной раны не влияло на функционирование шунта и в целом не сказывалось на косметичности. Указанная проблема нами частично решена более деликатным 
обращением с тканями (минимизация тракций и коагуляции) и наложением узловых швов на мягкие ткани вместо непрерывных обвивных. Однако при наличии анатомических особенностей пациента и удаленном взаимном расположении ЛВГА и ПМЖА, требующем значительной мобилизации ЛВГА, штатный инструментарий не позволяет ограничиться минимальной травмой, что создает предпосылки для осложнений.

Несмотря на указанные недостатки, имеются основания полагать, что мини-МКШ при монососудистом поражении ПМЖА является конкурентной альтернативой ЧКВ, особенно при выраженном кальцинозе, сложном бифуркационном поражении или окклюзии ПМЖА; а при многососудистом поражении ГКР, включающая мини-МКШ, при меньшей по сравнению с традиционным коронарным шунтированием операционной травме имеет сопоставимый отдаленный результат.

Существенным преимуществом мини-МКШ и гибридной реваскуляризации по сравнению с традиционным коронарным шунтированием мы считаем неприкосновенность аорты, сохранение правой внутренней грудной артерии и благоприятных условий для потенциальных повторных операций коронарного шунтирования стернотомным доступом в будущем.

Выводы. Мини-МКШ при монососудистом поражении ПМЖА при потенциальных трудностях для проведения ЧКВ является предпочтительной альтернативой последнему. При многососудистом поражении мини-МКШ может быть использовано в качестве этапа ГКР, что мы рассматриваем в качестве стратегии выбора у пациентов с дополнительными рисками или ограничениями для проведения традиционного КШ, однако эта стратегия применима у большинства пациентов с ИБС, и последнее слово перед выбором всегда остается за ними.

Дальнейшая минимизация травмы при МКШ обеспечивается путем применения эндоскопических технологий и предполагает смену инструментария.

\section{Литература}

1. Nambiar P. Minimally invasive coronary bypass using internal thoracic arteries via a left minithoracotomy: "the Nambiar Technique" / P. Nambiar, C. Mittal // Innovations (Phila). - 2013. - Vol. 8 (6). - P. 420-426. doi:10.1097/ IMI.0000000000000035.

2. Технология мини-инвазивного маммарно-коронарного шунтирования без дополнительного оснащения / А. В. Петков, Ю. Н. Скибо, В. В. Бойко [и др.] // Харківська хірургічна школа. - 2013. - № 3. C. 34-37.

3. Колесов В. И. Первый опыт лечения стенокардии наложением венечно-системных сосудистых устьев / В. И. Колесов // Кардиология. - 1967. - № 4. C. $20-25$.

4. Kolessov V. I. Mammary artery - coronary artery anastomosis as method of treatment for angina pectoris / V. I. Kolessov // J Thorac Cardiovasc Surg. - 1967. - Vol. 54. P. 535-44.

5. Minimally invasive coronary artery bypass grafting: a new method using an anterior mediastinotomy / M. C. Robinson, D. R. Gross, W. Zeman [et al.] // J Card Surg. 1995. - Vol. 10. - P. 529-36.

6. Left anterior descending coronary artery grafting via left anterior small thoracotomy without cardiopulmonary bypass // A. M. Calafiore, G. Di Giammarco, G. Teodori [et al.] // Ann Thorac Surg. - 1996. - Vol. 61. - P. 1658-65.

7. Comparative study of same sitting hybrid coronary artery revascularization versus off-pump coronary artery bypass in multivessel coronary artery disease / W. B. Bachinsky, M. Abdelsalam, G. Boga [et al.] // J Interv Cardiol. 2012. - Vol. 25. - P. 460-468.

8. Hybrid Coronary Revascularization Using Robotic Totally Endoscopic Surgery: Perioperative Outcomes and 5-Year Results / J. O. Bonatti, D. Zimrin, E. J. Lehr [et al.] // The Annals of Thoracic Surgery. - 2012. - Vol. 94. - P. e19201926.

9. Hybrid Coronary Revascularization for the Treatment of Multivessel Coronary Artery Disease: A Multicenter Observational Study / J. D. Puskas, M. E. Halkos, J. J. DeRose // J Am Coll Cardiol. - 2016. - Vol. 68 (4). - P. $356-$ 365.

\title{
Hybrid Coronary Revascularization Using Coronary Artery Bypass Grafting via Left Anterior Small Thoracotomy (Single Center Experience)
}

\author{
Pyetkov O. V. ${ }^{1}$, Polivenok I. V. ${ }^{2}$, Skibo Yu. M. ${ }^{1}$, Buchneva O. V. ${ }^{2}$, Boyko V. V. ${ }^{2}$ \\ ${ }^{1}$ Kharkiv Medical Academy of Post-graduate Education (Kharkiv) \\ ${ }^{2} \mathrm{SI}$ «V. T. Zayzev Institute of General and Urgent Surgery NAMS of Ukraine» (Kharkiv)
}

Hybrid coronary revascularization (HCR) combines such advantages of coronary artery bypass grafting (CABG) and percutaneous coronary intervention (PCI) as durable long-term result and low periprocedural risks.

Objective. To analyze of results of HCR using the minimally invasive direct coronary artery bypass grafting (MIDCAB) on the basis of single center experience.

Materials and methods. Thirty patients underwent MIDCAB with left internal thoracic artery to left anterior descending (LAD) via left anterior small thoracotomy. HCR was performed in eight of them.

Results and discussion. There were no conversions, in-hospital mortality and perioperative myocardial infarctions in the study group. Poor thoracotomy wound reparation was the main complication (and the main disadvantage) that occurred in 
8 (27\%) patients (seven of them presented with diabetes mellitus or obesity) but with no long-term adverse consequences. In late follow-up period one death occurred for unknown reasons in 13 months after MIDCAB. One patient experienced a relapse of angina in 4 years after HCR due to the stent occlusion.

Conclusions. MIDCAB is still a preferable alternative to PCI in patients with complex LAD lesions especially in centers with limited resources. It also could be used as a stage in HCR in such centers especially in patients with additional risks or limitations for traditional CABG.

Key words: minimally invasive coronary artery bypass grafting, hybrid coronary revascularizations.

\section{Гібридна коронарна реваскуляризація з використанням міні-інвазивного мамарно-коронарного шунтування (досвід одного центру)

\author{
Пєтков О. В. ${ }^{1}$, Полівенок І. В. ${ }^{2}$, Скібо Ю. М. ${ }^{1}$, Бучнєва О. В. ${ }^{2}$, Бойко В. В. ${ }^{2}$ \\ ${ }^{1}$ Харківська медична академія післядипломної освіти \\ ${ }^{2}$ ДУ «Інститут загальної та невідкладної хірургії імені В. Т. Зайцева НАМН» (Харків)
}

Гібридна коронарна реваскуляризація (ГКР) поєднує такі переваги коронарного шунтування і черезшкірних коронарних втручань (ЧКВ), як надійний віддалений результат і низькі перипроцедуральні ризики.

Мета роботи - аналіз результатів ГКР з використанням міні-інвазивного мамарно-коронарного шунтування (міні-МКШ) на основі досвіду одного центру.

Матеріали та методи. Міні-МКШ в передню міжшлуночкову артерію (ПМША) під прямим візуальним контролем доступом через передню міні-торакотомію було проведено 30 пацієнтам. Вісьмом з них проведена ГКР.

Результати та обговорення. В досліджуваній групі не відмічено госпітальної летальності та периопераційних інфарктів міокарда; до конверсій не вдавалися. Найбільш значущим ускладненням (і основним недоліком) було погане загоєння торакотомної рани, відмічене у вісьмох пацієнтів (27\%), з яких сім мали цукровий діабет або ожиріння, що, проте, не мало віддалених негативних наслідків. У віддаленому періоді стався один летальний випадок з невідомих причин через 13 місяців після міні-МКШ. Ще в одного пацієнта відмічено рецидив стенокардії через 4 роки після ГКР унаслідок оклюзії стента.

Висновки. Міні-МКШ $є$ переважною альтернативою ЧКВ у пацієнтів із складними ураженнями ПМША, особливо в центрах з обмеженими ресурсами. Воно також може бути використане як етап ГКР у таких центрах, особливо у пацієнтів з додатковими ризиками або обмеженнями для традиційного коронарного шунтування.

Ключові слова: міні-інвазивне мамарно-коронарне шунтування, гібридна коронарна реваскуляризація. 